\title{
The Study of Burning Behavior of Cotton/Glass Woven Fabrics
}

\author{
Mosen Gorji* and Ali AA Jeddi \\ Departement of Textile, Amirkabir University of Technology, Iran \\ *Corresponding author: Mosen Gorji, Departement of Textile, Amirkabir University Of Technology, Iran
}

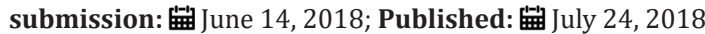

\begin{abstract}
In this research we investigated the effects of some structural parameters of woven fabrics on their flame resistance. The samples were weaved from different yarn to optimize the flame resistance of fabric. Also this research develops a special method to prevent ignition propagation through a protective fabric that exposed flame using of glass yarn barrier in cotton fabric. Experimental studies of fabric flammability and fabric burning behaviors are carried out based upon standard test method (BS 5438) and a simulation proposed method.
\end{abstract}

Finally, experimental results were evaluated statistically using a MANOVA method. The results showed density have significant effect in both method but the glass barrier has different behavior. The statistic models were obtained to predict the flame spread in different area of fabric and the extend of spread of flame.

Keywords: Woven fabrics; Structural properties; Ignition propagation; Glass yarn barrier; Statistical model

\section{Introduction}

Textile combustion is a complex phenomenon [1] that involves heating, decomposition leading to gasification (fuel generation), ignition, and flame propagation. A self- sustaining requires a fuel source and means of gasifying the fuel and mixing the gaseous fuel with oxygen and heat. For protective clothing, there are several requirements, such as protection against heat by providing insulation, as well as high dimensional stability of fabric that, upon exposure to heat fluxes in carrying out the wearer's work, will not shrink, melt or form chars that may disintegrate if the wearer move.

Four ways of stopping combustion have been suggested, heat may be removed or cooling applied, the increase in pyrolysis temperature makes the material heat resistant; glass, semi-carbon fibers and aramid fibers are extremely stable and heat resistant, the third way of stopping combustion is to prevent evaporation, that is, to form char, combustion may be prevented by eliminating the oxygen from the combustion zone and thus stopping oxidation.

Important aspects of fire hazards of a fabric are expressed by ease of ignition, rate and extend of spread of flame and amount of heat evolved. In addition, the duration of flaming, the temperature

\section{Experimental}

\section{Materials}

Table 1: The structural properties of samples. at the surface of a burning fabric and the ease of extinction are important for studying the performance of a heat protective garment. Krasny and his co-workers have observed that many heavy fabrics are less easily extinguished than light fabrics and may burn longer in accidents [2]. Miller et al studied extingiushability or the ease with which an ignited fabric is extinguished, by determining the burning rates as a function of environmental oxygen index concentration [3].

Most research directed toward improving the flame resistance characteristics of these materials has been based on chemical treatments and changes in molecular structure [3-8]. However, inherently fire-resistant fibers and fiber systems containing fire retardant additives will still burn under sufficiently sever thermal conditions. In this way, it will be possible to produce end products with suitable physical and burning properties for used in the field. Fabric weight, air permeabilities, and cover factors cause change in the flame retardancy characteristics of fabrics, [7-11]. Accordingly, we have conducted research of plain-woven fabrics to investigate the effects of their properties on flame resistance. For this purpose we used glass yarn as a barrier to prevent from fabric combustion.

\begin{tabular}{|c|c|c|c|c|c|}
\hline $\begin{array}{c}\text { The Number of Glass Yarn } \\
\text { Some Weave Parameters }\end{array}$ & $\mathbf{0}$ & $\mathbf{1}$ & $\mathbf{2}$ & $\mathbf{4}$ \\
\hline Weft density $\left(\mathrm{cm}^{-1}\right)$ & $8,10,12$ & $8,10,12$ & $8,10,12$ & $8,10,12$ & $8,10,12$ \\
\hline
\end{tabular}




\begin{tabular}{|c|c|c|c|c|c|}
\hline Weft linear density $(\mathrm{Ne})$ & 5 & 5 & 5 & 5 & 5 \\
\hline Warp density $\left(\mathrm{cm}^{-1}\right)$ & 10 & 10 & 10 & 10 & 10 \\
\hline Warp linear density $(\mathrm{Ne})$ & $20-\mathrm{Feb}$ & 20 -Feb & 20 -Feb & 20 -Feb & 20 -Feb \\
\hline
\end{tabular}

Gray fabrics were produced in plain weave pattern with three different yarn densities. The fabrics evaluated are summarized in Table 1.

The fiber should have a low thermal conductivity, and also should not soften at higher temperatures. It may also be noted that aramid and glass fibers in spite of their high oxygen index $[3,12]$ and high thermal ability, have not be found suitable for preventing skin burns in molten metal splashes because of their high thermal conductivity. The glass yarns are weaved as weft in each three yarn density in matrix of cotton yarn to investigate the effect of exist some barriers (flame resistance yarn) and to achieve optimum protection. The number of glass yarn that placed near each other as barrier were four cases in each yarn density; one, two, three and four barrier yarns and the distance between successive barriers in all samples are constant two centimeters that was equal with flame height to reduce the fuel source from burning zone and stop or reduce flame spread speed.

Specification of fabric, weight per unit area in $\mathrm{g} / \mathrm{m}^{2}$, air permeability in $\mathrm{mm} / \mathrm{s}$, and fabric thickness in $\mathrm{mm}$ were determined for the fabrics produced fabrics (Table 2).

Table 2: The average of measured parameters.

\begin{tabular}{|c|c|c|c|c|c|c|c|c|c|}
\hline $\begin{array}{l}\text { Weft Density } \\
\text { (Cm-1) }\end{array}$ & $\begin{array}{c}\text { The Number } \\
\text { of } \\
\text { Glass Yarn }\end{array}$ & $\begin{array}{l}\mathrm{RI30} \\
(\mathrm{Cm} / \mathrm{S})\end{array}$ & $\begin{array}{l}\mathrm{Rl60} \\
(\mathrm{Cm} / \mathrm{S})\end{array}$ & $\begin{array}{c}\text { Ease of } \\
\text { Extinction } \\
\text { (S) }\end{array}$ & $\begin{array}{l}\text { Glowing } \\
\text { Spread } \\
\text { Speed } \\
(\mathrm{Cm} / \mathrm{Min})\end{array}$ & $\begin{array}{c}\text { Extend of } \\
\text { Spread } \\
\text { of Flame }\end{array}$ & $\begin{array}{l}\text { Thick- } \\
\text { ness } \\
\text { (Mm) }\end{array}$ & $\begin{array}{c}\text { Air Permeability } \\
(\mathrm{Mm} / \mathrm{S})\end{array}$ & $\begin{array}{c}\text { Weight Per } \\
\text { Unit Area } \\
\left(\mathrm{Kg} / \mathrm{m}^{2}\right)\end{array}$ \\
\hline 12 & 0 & 2.44 & 3.04 & 11.75 & 1.33 & 0.99 & 0.75 & 12.75 & 0.24 \\
\hline 12 & 1 & 2.63 & 3.34 & 12.41 & 1.3 & 0.95 & 0.76 & 13.21 & 0.25 \\
\hline 12 & 2 & 3.8 & 3.42 & 12.75 & 1.28 & 0.59 & 0.8 & 12.5 & 0.26 \\
\hline 12 & 4 & 2.8 & 3.6 & 12.76 & 1.23 & 0.59 & 0.81 & 12.58 & 0.25 \\
\hline 12 & 8 & 2.95 & 3.03 & 10.78 & 1.22 & 0.57 & 0.79 & 12.5 & 0.24 \\
\hline 10 & 0 & 3.3 & 3.72 & 13.8 & 1.84 & 0.95 & 0.8 & 15.58 & 0.22 \\
\hline 10 & 1 & 3.52 & 3.83 & 11.99 & 1.27 & 0.85 & 0.77 & 15.46 & 0.22 \\
\hline 10 & 2 & 3.15 & 3.73 & 14.2 & 1.35 & 0.91 & 0.77 & 14.42 & 0.23 \\
\hline 10 & 4 & 3.1 & 3.66 & 8.96 & 0.99 & 0.85 & 0.82 & 16.42 & 0.22 \\
\hline 10 & 8 & 3.57 & 4.24 & 8.32 & 1.46 & 0.88 & 0.75 & 15.03 & 0.21 \\
\hline 8 & 0 & 3.14 & 4.01 & 7.98 & 1.83 & 0.95 & 0.88 & 17.71 & 0.2 \\
\hline 8 & 1 & 3.22 & 3.83 & 5.69 & 1.61 & 0.98 & 0.88 & 18.75 & 0.19 \\
\hline 8 & 2 & 3.31 & 3.87 & 6.98 & 1.55 & 1 & 0.85 & 19.83 & 0.19 \\
\hline 8 & 4 & 3.58 & 4.3 & 7.76 & 1.51 & 0.89 & 0.92 & 19.75 & 0.19 \\
\hline 8 & 8 & 3.76 & 4.41 & 3.49 & 0.77 & 0.35 & 0.79 & 21.25 & 0.19 \\
\hline
\end{tabular}

\section{Methods}

Flame spread speed: Since the $90^{\circ}$ orientation may be assumed to correspond most closely to the situation of textile fabrics used in garments, we chose the BS 5438 vertical flammability test method to evaluate flame spread rates [11]. This test has achieved the widest acceptance for determining the flame and glow resistance of fabrics [2].

For each fabric type, three fabric specimens, $170 \times 670 \mathrm{~mm}$ length and width, were prepared and conditioned for 24 Hours before testing. The conditioned specimens were then mounted in a suitable clamp and placed in a standard cabinet that allows $2 \mathrm{~mm} /$ second airflow, and the bottom edge of the fabric was exposed to a standard flame. In order to consider the flame spread speed three marked line were made on the mounted specimens at 2, 32 and $62 \mathrm{~cm}$ from the bottom edge of fabric. The moments that flame reach to any of these lines was recorded by video camera. The speed of flame spread was obtained by dividing the length that burned to the time that was recorded. Flame spread speed(R $\mathrm{mm} / \mathrm{s}$ ) for the first 30 and $60 \mathrm{~cm}$ were determined for all fabric specimens. The $\mathrm{R}$ value, because it does consider the rate at with a flame propagates, is acceptable as a measure of flammability [11].

Garment burning simulation: In order to represent actual human-response conditions, a simulated 'beating hand' was used to extinguish burning fabrics. Many fabrics stop burning on contact with a mannequin or living skin. The apparel flammability modeling apparatus (AFMA) represent two extremes occurring during reallife apparel fires; in the free-hanging mode, the specimens hang freely from a frame suspended near the top of the semi-cylinder, which is inclined at $20^{\circ}$ to the vertical and remains in this position throughout the test. In contact mode when one of the four sensors 
registers a heat rise of $5^{\circ} \mathrm{C}$ the semi-cylinder moves to the vertical position and makes contact with the specimen. This simulates movement of, for example, a leg in burning trousers [2].

In this part with regard to these works a simple method for garment burning simulation was designed to represent actual human-response conditions. The specimens are located on a flat plate in a manner that were with contact with the plate except in the bottom of the plate where two centimeters of samples were free [13], although in contact mode there was randomly air between fabric and plate at some point. The plate located vertically in the cabin that described in previous part and the bottom of fabric was exposed to flame. It was observed that when flame reached to the area where fabrics were with contact with the plate the flame extinct and continues with glowing. This can simulate the apparels that are in contact with body in some area.

To quantity garment burning simulation three parameters are defined according to the observation as follows and their determined result are shown in Table 2.

\section{A. Ease of extinction}

Usually in garment burning simulation there are two modes, contact mode and free hanging mode and many fabrics stop burning in contact with a mannequin or living skin $[2,14]$. It was observed that when flame reached to the area where fabrics were with contact with the plate the flame extinct and continues with glowing. Ease of extinction was studied by determining the time

Table 3: The MANOVA results for flame spread speed. when sample is ignited and when is extinguished. As this parameter be smaller the ease with which an ignited fabric is extinguished, is better and the burning resistance of fabric is higher.

\section{B. Extend of spread of flame}

This parameter is expressed by the ratio of burned fabric area (char area) to initial sample area. It is obvious that as this parameter is smaller the amount of heat evolved in combustion phenomenon is less.

\section{Glowing spread speed}

Glowing is combustion of a material in the solid phase with emission of light from the surface [15]. It is observed that when the burning fabric extinguished the samples glowed. This value is the result of dividing the length that glowed to the time that is needed and expressed in $\mathrm{cm} / \mathrm{min}$.

\section{Results and discussion}

\section{The effect of yarn density and glass barrier on flame spread speed}

After the physical tests, we conducted a vertical flammability and garment burning simulation test on each specimen. Once results were acquired, they were treated statistically with the help of multivariate analysis of variance (MANOVA) tables to indicate the general effect of yarn density and glass barrier on the flame spread speed. The result has shown in Table 3.

\begin{tabular}{|c|c|c|c|}
\hline Effective Parameter & The effect of weft density & $\begin{array}{c}\text { The effect of barrier } \\
\text { (glass yarn) }\end{array}$ & weft density $\chi$ barrier yarn \\
\hline $\begin{array}{c}\text { Flame spread speed } \\
\text { at first } 30 \mathrm{~cm}\end{array}$ & $* *$ & $*$ & $*$ \\
\hline $\begin{array}{c}\text { Flame spread speed } \\
\text { at } 60 \mathrm{~cm}\end{array}$ & $* * *$ & $*$ & $*$ \\
\hline
\end{tabular}

Table 4: Dancan subgroup for the effect of weft density on flame spread speed $(\mathrm{cm} / \mathrm{s})$.

\begin{tabular}{|c|c|c|}
\hline \multirow{2}{*}{ Weft Density } & Subgroup & \\
\cline { 2 - 3 } & $\mathbf{1}$ & $\mathbf{2}$ \\
\hline $12 / \mathrm{cm}$ & 3.29 & \\
\hline $10 / \mathrm{cm}$ & & 3.84 \\
\hline $8 / \mathrm{cm}$ & & 4.08 \\
\hline
\end{tabular}

(A)

\begin{tabular}{|c|c|c|}
\hline \multirow{2}{*}{ Weft Density } & \multicolumn{2}{|c|}{ Subgroup } \\
\cline { 2 - 3 } & $\mathbf{1}$ & $\mathbf{2}$ \\
\hline $12 / \mathrm{cm}$ & 2.99 & \\
\hline $10 / \mathrm{cm}$ & & 3.33 \\
\hline $8 / \mathrm{cm}$ & & 3.4 \\
\hline
\end{tabular}

(B)

A) $60 \mathrm{~cm} \mathrm{B)} 30 \mathrm{~cm}$
As it is revealed from P-value the yarn density in first 30 centimeter at $98 \%$ confidence level and in 60 centimeter at $99 \%$ confidence level has significant effect. Dancan subgroup results (Table 4) show the flame spread speed in 60 centimeters is faster than first 30 centimeters, we can say burning of initial part of fabric evolved some heat and this heat raised the temperature of remain fabric (the test method is vertically and samples are located vertically) and its surrounding that lead to fuel source (fabric) need less amount of energy to reach to the pyrolys temperature and subsequent burning temperature so they burn faster.

The ANOVA test (Table 3) shows no significant effect for glass barrier, that means exist of glass yarn- that is inherently flame resistant- has no effect on flame spread speed. This result is investigable from two views:

First, As Table 4 shows the maximum weight ratio of glass yarns to cotton yarns i.e. minimum of yarn density ( 8 thread/cm) and 8 glass yarn is only 0.258 , also in the area where there are glass yarn, the fuel source was not omitted completely because of warp cotton 
yarn that help to duration of flame propagation. Further yarn glasses have higher heat transfer index than cotton yarn and act as a duct to transfer heat to the next areas and this help these areas ignite faster. Second, this result is reveals this fact that glass and cotton yarn didn't has any negative inter action or fuel effect similar what pointed in introduction for cotton and polyester blend- that is good result to permit production fabric from these two yarns with optimal properties (Table 5).

Table 5: The weight ratio of glass yarn to cotton yarn.

\begin{tabular}{|c|c|c|c|}
\hline \multicolumn{1}{|c|}{ Weft Density } & & & \\
\cline { 1 - 3 } The Number of Glass Yarn & $\mathbf{8}$ & $\mathbf{1 0}$ & $\mathbf{1 2}$ \\
& & & \\
\hline 1 & & & 0.03 \\
\hline 2 & 0.03 & 0.03 & 0.05 \\
\hline 4 & 0.06 & 0.06 & 0.11 \\
\hline 8 & 0.13 & 0.12 & 0.21 \\
\hline
\end{tabular}

\section{Modeling the flame spread speed in cotton fabric}

The linear regression analyses were carried out to provide a statistical model for prediction flame spread speed if structural parameters changed. The below linear equation defined as:

$$
\mathrm{Rl}_{30}=.037 \mathrm{~A}-.153 \mathrm{~W}-.031 \mathrm{~T}+1.043 \text { (1) }
$$

Where $\mathrm{R}_{30}=$ flame spread speed for specimens at first $30 \mathrm{~cm}$, A: air permeability $(\mathrm{mm} / \mathrm{s}), \mathrm{W}$ : weight per unit area $\left(\mathrm{kg} / \mathrm{m}^{2}\right)$, T: thickness (mm).

ANOVA analyses for confirmation linearity of model was significant at 99\% confidence level (P-Value $<0.00)$.

Various researchers have suggested that final inches of the fabrics burn faster than the initial inches and Ozcan suggested a linear regression model for this concept as follows:

$$
\mathrm{R}_{60}=-4.165+0.580 \mathrm{R}_{30}+1.877 \mathrm{Rw}+.0623 \text { ignition time }
$$

$\mathrm{R}_{60}=$ flame spread speed for specimens at $60 \mathrm{~cm}, \mathrm{R}_{30}=$ flame spread speed for specimens at first $30 \mathrm{~cm}, \mathrm{Rw}=$ flame spread speed widthwise [11].

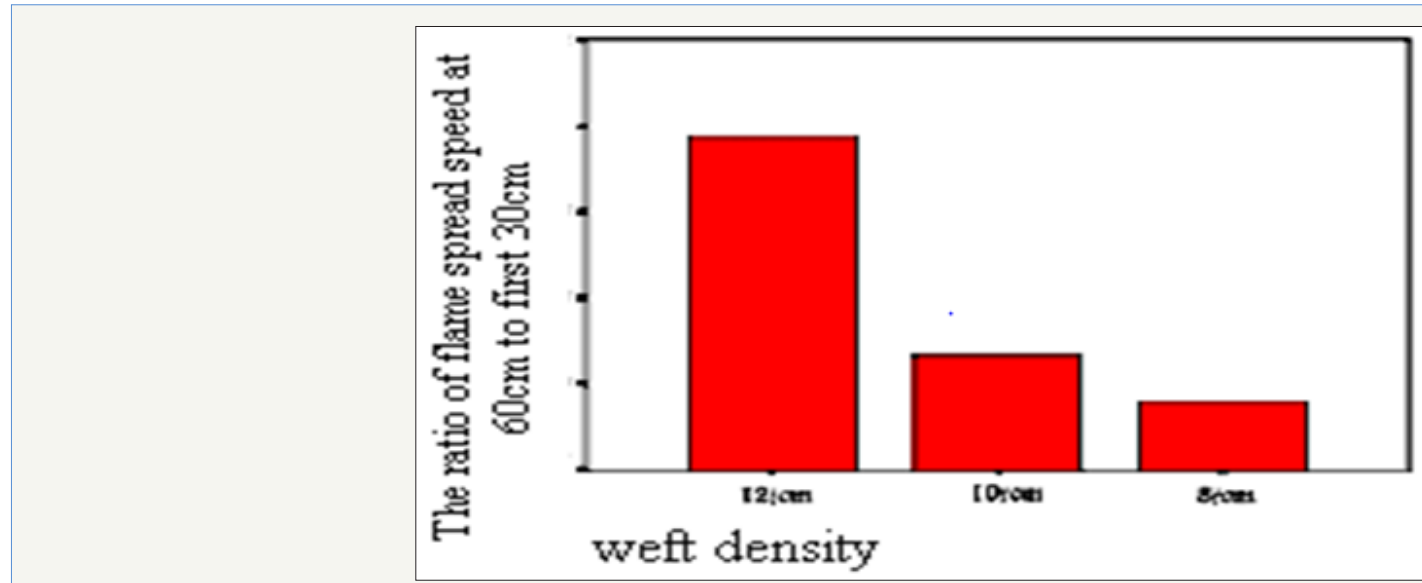

Figure 1: The ratio of flame spread speed at 60 centimeter to flame spread speed at 30 centimeter.

As it has been shown in Figure 1 the ratio of flame spread speed at 60 centimeter to flame spread speed at 30 centimeter changed with the changing of parameters (weft yarn density or weight per

\section{Garment burning simulation}

Table 6: The result of MANOVA for simulated model.

\begin{tabular}{|c|c|c|c|}
\hline $\begin{array}{c}\text { The Effective Parameters } \\
\text { Defined Parameters }\end{array}$ & $\begin{array}{c}\text { The Effect of } \\
\text { Weft Density }\end{array}$ & $\begin{array}{c}\text { The Effect of Barrier } \\
\text { (Glass Yarn) }\end{array}$ & Weft Density×Barrier \\
\hline Extend of spread of flame & Significant (p-value0.01) & Significant (p-value0.01) & No Significant \\
\hline Glowing spread speed & Significant (p-value0.01) & Significant (p-value0.01) & No Significant \\
\hline Ease of extinction & Significant (p-value0.01) & No Significant & No Significant \\
\hline
\end{tabular}

The effect of weft yarn density and glass barrier yarn: In this part the effect of yarn density and glass barrier yarn were studied using MANOVA method and the result were shown in Table 6. As it is considered glass barrier yarn has significant effect at $98 \%$ unit area, etc). Therefore the following model has been suggested for flame spread speed at 60 centimeter:

$$
\mathrm{R}_{60}=1.02 \mathrm{R}_{30}+0.42 \mathrm{~A}-1.63 \mathrm{~W}-0.016(2)
$$

confidence level on Extend of spread of flame and at 95\% confidence level on Glowing spread speed. With increasing the number of glass yarn barriers the values of extend of spread of flame and glowing spread speed decreased but glass barrier yarn has no effect on 
ease of extinction. From this result and with regard to the result of flame spread speed that glass barrier yarn didn't have any effect on it, it can be concluded that in situation that there is not flame and the heat evolution is low the barrier has desired effect that it will be achieved by finishing cotton with flame retardant material or using flame resistance yarn, and then not only the flame retardant fabric will be produced but also the heat transfer properties of fabrics reach optimize situation. Eight and four glass yarn have minimum value for extend of spread of flame and glowing spread speed and zero and one glass yarn has maximum value.

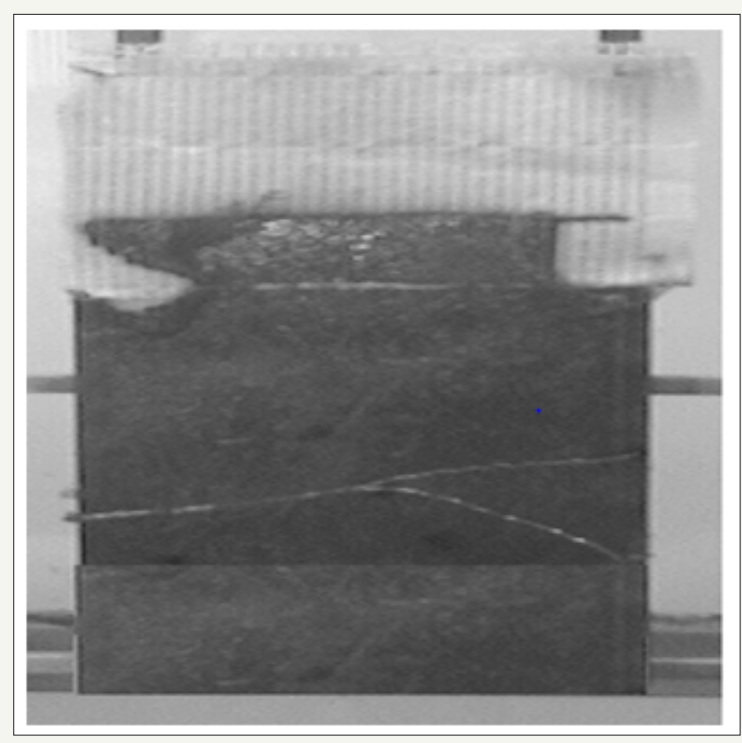

Figure 2: Glowing propagation in contact with barrier.

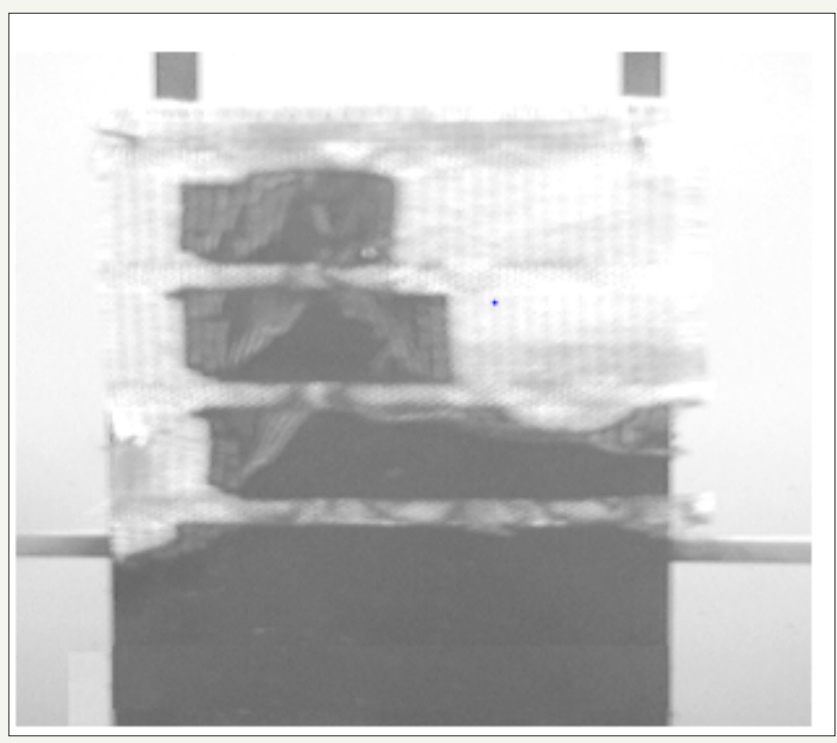

Figure 3: The effect of barrier on the glowing propagation.

Observation: Although, there is no difference between the glowing of the fabrics with one glass yarn barrier and without yarn barrier, but the former has stable structure after burning. But when two or more glass yarns are used, it was observed that the after glowing in contact with these barriers was stopped in length direction and burning extends in width direction parallel with barrier yarn (Figure 2). The fabrics which are produced with two and more number glass yarns specially in a more compact weft density, the width of flame when reached to the glass barrier in the most of its width is getting extinction and mostly the flame penetrate only through away in a narrow path. Then, and after crossing the barrier again spread in width direction but the maximum width that achieved is less than the previous part (Figure 3).

The modeling of extend of spread of flame in simulated model: Because of the importance of the extend of spread of flame (the ratio of the area of burned fabric to the initial area) following statistical model has been provided:

$\mathrm{E}=-0.156 \mathrm{~W}-0.387 \mathrm{G}+0.065 \mathrm{~A}-24.261 \mathrm{~T}+73.175(3)$ 
Where $\mathrm{E}$ is Extend of spread of flame, $\mathrm{G}=$ the number of glass barrier, $\mathrm{W}=$ weight per unit area, $\mathrm{A}=$ air permeability and $\mathrm{T}$ is fabric thickness (Table 7A \& 7B).

Table 7A: Dancan subgroup for extend of spread of flame based on the number of glass yarn.

\begin{tabular}{|c|c|c|c|}
\hline \multirow{2}{*}{$\begin{array}{c}\text { The Number of } \\
\text { Glass Yarn }\end{array}$} & \multicolumn{3}{|c|}{ Subgroup } \\
\cline { 2 - 4 } & $\mathbf{1}$ & $\mathbf{2}$ & $\mathbf{3}$ \\
\hline 8 & 0.73 & & \\
\hline 4 & 0.79 & 0.79 & \\
\hline 2 & & 0.91 & 0.91 \\
\hline 1 & & 0.94 & 0.94 \\
\hline 0 & & & 0.97 \\
\hline
\end{tabular}

Table 7B: Dancan subgroup for Glowing spread speed based on the number of glass yarn.

\begin{tabular}{|c|c|c|}
\hline \multirow{2}{*}{$\begin{array}{c}\text { The Number of } \\
\text { Glass Yarn }\end{array}$} & $\mathbf{2}$ & $\mathbf{2}$ \\
\cline { 2 - 3 } & $\mathbf{1}$ & \\
\hline 8 & 1.27 & 1.36 \\
\hline 4 & 1.36 & 1.37 \\
\hline 2 & 1.37 & 1.41 \\
\hline 1 & 1.41 & 1.68 \\
\hline 0 & & \\
\hline
\end{tabular}

\section{Conclusion}

The results of this study indicate that

1. As it is expected flame spread speed increase with the decrease of weft density.

2. As it was shown in previous researches, flame spread speed at the ending parts of fabric is faster than initial part of fabric.

3. 3-Glass barrier has no significant effect-nether positive nor negative effect- on flame spread speed.

4. 4-A regression model for flame spread speed at first $30 \mathrm{~cm}$ is presented as below:

i. $\quad \mathrm{Rl}_{30}=0.037 \mathrm{~A}-0.153 \mathrm{~W}-0.031 \mathrm{~T}+1.043$
5. 5-A regression model for flame spread speed at $60 \mathrm{~cm}$ in terms of flame spread speed at first $30 \mathrm{~cm}$ and other main structural parameters is given as below

a. $\mathrm{R}_{60}=1.02 \mathrm{R}_{30}+0.42 \mathrm{~A}-1.63 \mathrm{~W}-0.016$

6. 6-In simulated model, glass barrier has significant effect on extend of spread of flame and glowing spread speed and has no significant effect on ease of extinction. With increasing the number of glass barrier extend of spread of flame and glowing spread speed decrease. A regression model for Extend of spread of flame is provided.

\section{i. $\quad E=-0.156 \mathrm{~W}-0.387 \mathrm{G}+0.065 \mathrm{~A}-24.261 \mathrm{~T}+73.175$}

7- As it is expected with increasing fabric weight and density, the fabric's resistance against burning will be increased.

\section{References}

1. Horrocks AR, Sheng Z (1986) Rev Prog col 62.

2. Pushpa B, Sengupta AK (1992) Textile Inst Textile Prog 22(1).

3. Horrocks A, Tunc M (1989) Textile Inst Textile Prog 18.

4. Car CM (1995) Chemistry of the Textile Industry, University Press, Cambridge, UK.

5. Mayer D (1992) Textile Month 53.

6. Chapman AC, Miller G (1980) J Coated Fabr 10: 26.

7. Mehta PN (1980) Textile Res J 185.

8. Benisek L, Edmondson GK, Textile Res J182.

9. Lewin M (1990) Handbook of fiber science and technology. $2^{\text {nd }}$ edn, Dekker, USA.

10. Dambournet A (1982) Protective clothing. $11^{\text {th }}$ edn, Shirley Institute, UK. 11. Gulay O, Habip D, Cevaza C (2003) Textile Res J 73: 883.

12. Lilani HN (1996) Norfab corporation. US Patent, 5506043.

13. Lilani HN (1996) Norfab corporation. US Patent, 5496625.

14. Guowen S, Roger LB, Hechmi H, Andrey V K, Patirip C, et al. (2004) Textile Res J 74: 1033

15. (1976) BS flammability of vertically oriented textile fabrics and fabric assemblies subjected to a small igniting flame, B Standard 5438.
Creative Commons Attribution 4.0 International License

For possible submissions Click Here

\section{Submit Article}

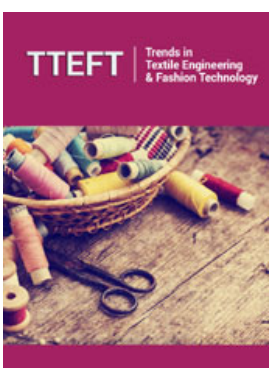

Trends in Textile Engineering \& Fashion Technology

\section{Benefits of Publishing with us}

- High-level peer review and editorial services

- Freely accessible online immediately upon publication

- Authors retain the copyright to their work

- Licensing it under a Creative Commons license

- Visibility through different online platforms 